\title{
Impacto da ascensão chinesa sobre os países latino-americanos
}

\author{
CARLOS AGUIAR DE MEDEIROS \\ MARIA RITA VITAL PAGANINI CINTRA*
}

RESUMO: Este trabalho faz uma revisão da expansão das relações econômicas entre a China e os países da América Latina na última década. O grande processo de urbanização chinesa foi o principal estímulo para as exportações de commodities desses países e a China tornou-se o maior mercado para exportação e grande fornecedor de produtos manufaturados para muitos dos países da América Latina, assim como também tem ampliado sua contribuição para investimento e crédito. Nesse processo de reestruturação da divisão internacional do trabalho consideramos dois efeitos diferentes, um "efeito de demanda" e um "efeito de estrutura" e iinvestigamos como a complementaridade e as pressões competitivas afetou o comércio dentro da região e nos países de acordo com seus diferentes padrões e estrutura produtiva.

PALAVRAS-CHAVE: China; América Latina; padrões do comércio; complementaridade; concorrência; comércio.

ABSTRACT: The impact of China's rise on Latin-AAmerican countries. We review in this paper the expansion of economic relations between China and Latin America Countries (LAC) in the last decade. The large process of Chinese urbanization was the main driver for LAC commodity exports and China became the largest market for export and large supplier of manufactures for many LAC and its contribution for investment and credit has enlarged as well. In this process of restructuring of international division of labor we considered two different effects, a "demand effect" and a "structure effect" and investigated how complementarity and competitive pressures affected trade within region and in LAC according to their different patterns and productive structure.

KEYWORDS: China; Latin America; trade patterns; complementarity; competition; trade. JEL Classification: O1; O5; F1; F4; F6.

\footnotetext{
* Professor do Instituto de Economia da Universidade Federal do Rio de Janeiro e pesquisador do CNPQ. E-mail: carlosaguiarde@gmail.com; Mestre em Economia Política Internacional, Programa de Pós-Graduação em Economia Política Internacional, da Universidade Federal do Rio de Janeiro, e-mail: maria.paganini@uol.com.br. Submetido: 1/Abril/2014; Aprovado: 17/Junho/14.
} 


\section{INTRODUÇÃO}

Em seu "Manifesto", Raul Prebisch (1950) argumentou que a mudança do centro cíclico principal para os EUA tornava o modelo de crescimento latino-americano baseado nas exportações de produtos primários e complementar à estrutura produtiva industrial inglesa incapaz de gerar o ritmo de crescimento e de investimentos previamente observado na região. Embora Prebisch tenha salientado a tendência à deterioração dos termos de troca como argumento central desta formulação, sua proposição mais geral combinava tanto a evolução dos preços quanto das quantidades demandadas de bens primários e industriais resultante da evolução dos padrões de consumo e da tecnologia e do fim da complementaridade entre o centro (os EUA) e a periferia (a América Latina).

Após 50 anos de persistente declínio dos termos de troca - brevemente interrompidos no início dos anos 1950 e dos 1970 - e distintas estratégias de acumulação, como a industrialização por substituição de importações (entre 1950 e 1980) e a de abertura produtiva e financeira nos anos 1990, a América do Sul passou por uma realidade externa distinta nos anos 2000. Nesta década, a forte elevação no preço das commodities, a mudança dos termos de troca e a forte demanda externa por bens primários destravaram as restrições de balanço de pagamentos que se avolumaram entre 1998 e 2003. A grande demanda chinesa por recursos naturais foi indiscutivelmente um fator central deste novo cenário externo dos países sul -americanos.

A despeito de baixos valores iniciais, o crescimento do comércio entre commodities exportadas pela região e bens industriais exportados pela China — se deu a taxas excepcionais, adicionalmente ampliou substancialmente sua posição como investidor. Com exceção do México — um grande exportador de bens industriais rivais com a produção chinesa - que registrou grande déficit comercial com a China, na América do Sul - com um padrão de comércio complementar — o déficit bilateral foi menor e, em muitos países, registrou-se um superávit.

Os países da América do Sul aproveitaram as novas condições externas para elevar sua taxa de crescimento e expandir os mercados internos. O forte crescimento dos fluxos financeiros que se afirmou no período se deu num contexto de elevação simultânea das exportações reduzindo a fragilidade externa anterior. Adicionalmente maiores controles nacionais sobre os recursos naturais e iniciativas favorecedoras ao alargamento do processo de regionalização foram difundidos. Entretanto, poucas iniciativas visando maior diversificação produtiva foram construídas. A crescente rivalidade das exportações chinesas, tanto no mercado interno quanto nos mercados externos, particularmente no MERCOSUL, gerou deslocamentos absolutos ou relativos em seus mercados industriais. Com a crise global de 2008 e persistente contração da União Europeia nos anos posteriores o crescimento das importações chinesas tornou-se ainda mais significativo para a região e para a sustentação geral dos termos de troca. Mas ao mesmo tempo, com a desaceleração do crescimento econômico em algumas economias da região pós-2009 particularmente no Brasil, a rivalidade com as exportações procedentes da China 
aumentaram e, do mesmo modo ampliaram as diferenças entre os países em relação aos acordos de livre comércio com a China e o comércio regional.

Tendo em vista este contexto objetiva-se neste texto investigar o efeito da ascensão chinesa sobre a América Latina sublinhando os diferentes impactos e possibilidades abertas. O artigo divide-se em cinco seções. Na primeira seção discutese a ascensão chinesa e seu impacto sobre o comércio e os preços relativos, na segunda seção examina-se o "efeito demanda" e o "efeito estrutura" desta expansão sobre seus principais parceiros, na terceira seção examina-se a expansão chinesa na América Latina, na quarta seção discute-se o seu impacto diferenciado entre os países do continente, na quinta seção conclui-se o texto.

\section{OS DOIS MOTORES DA ASCENSÃO CHINESA E SEUS IMPACTOS NA ECONOMIA MUNDIAL}

Entre 2005 e 2010 a China transformou-se no maior país exportador mundial, e no segundo maior importador, atrás apenas dos EUA (Farooki e Kaplinsky, 2012). Ainda que as economias industrializadas possuam a maior corrente de comércio com a China, o comércio desta com os países em desenvolvimento aumentou substancialmente do mesmo modo os investimentos e financiamentos externos chineses aumentaram substancialmente, excepcionalmente concentrados em mineração e petróleo.

A ascensão chinesa no centro do comércio mundial e na divisão internacional do trabalho decorre de dois processos que, embora inter-relacionados, possuem autonomia e dinâmicas específicas. O primeiro é a grande urbanização ${ }^{1}$ e a industrialização pesada com ela articulada. Acelerado desde os anos 1990, este processo se transmite diretamente para a economia mundial, principalmente através da demanda por energia, minerais e alimentos ${ }^{2}$. Devido à extraordinária combinação entre o tamanho de sua população e produção industrial e a baixa renda per capita, o processo de urbanização e modernização do consumo chinês é fortemente intensivo em matéria-prima e energia. Ao lado da estrutura produtiva diretamente associada à construção civil, a China transformou-se no maior produtor mundial de automóveis e veículos, levando à grande expansão na indústria metal mecânica (Farooki e Kaplinsky, 2012).

A despeito de ser grande produtor mundial das principais commodities agrícolas, metais e energia, o consumo interno cresceu a taxas muito superiores às da

\footnotetext{
${ }^{1}$ Em 1980 a população urbana era inferior a 200 milhões, 30 anos depois abrigavam 500 milhões. Na última década, 100 milhões chineses migraram do campo para as cidades (Miller, 2012). A perspectiva e as metas estabelecidas no $12^{\circ}$ Plano Quinquenal (2011-15) é de que esta tendência vai se aprofundar nas próximas décadas.

${ }^{2}$ Farooki e Kaplinsky (2012) classificam as commodities em três grupos: as "commodities macias" formadas pelos produtos agrícolas (cereais, bebidas, carne, pescado, algodão, madeira); as "commodities duras" (minerais como metais preciosos, ferro, não ferrosos, minérios raros) e energia. Ao longo deste texto, esta classificação será referida como commodities agrícolas, minerais e energia.
} 
produção, levando a grande demanda por importações. Conjugado com esta demanda estrutural se deu a internacionalização das grandes empresas estatais chinesas (Sinopec, CNPC, CNOOC, State Grid Corporation, Golden Dragon Precise Cooper Tuhe Group, Chinalco, etc.) fortemente concentrada no comércio, mineração e petróleo. Em 1995, a parcela da China como destino das exportações mundiais de produtos alimentares, matérias-primas agrícolas, metais e energia era respectivamente de $2,3 \% ; 5.4 \% ; 2,5 \%$ e $1,5 \%$; em 2012 , atingiram $6,2 \% ; 23,8 \%$; 20,1\% e 8,3\% (UNCTAD, Handbook, 2013).

Ao lado do seu impacto sobre a demanda, a expansão chinesa teve substancial impacto sobre o preço de algumas commodities como a soja, e os metais ${ }^{3}$. O que distingue a mudança no ciclo de preços das commodities iniciado nos anos 2000 é a sua persistência - a queda nas altas de preços em 2008 e as intensas flutuações nos anos posteriores não anularam a forte mudança inicial - ao contrário do que se passou nos ciclos precedentes, do início dos anos 1950 e início dos 1970 quando após forte elevação os preços retornaram aos níveis iniciais (Farooki e Kaplinsky, $2012)^{4}$. A ascensão chinesa é parte desta diferença. Em conjunto com seu efeito os preços industriais, sobretudo nas indústrias intensivas em mão de obra, a industrialização e urbanização chinesas contribuíram para a "quebra estrutural" observada nos termos de troca. Nas economias em desenvolvimento da África estes passaram de 100 em 2000 para 182 em 2012; na América do Sul de 100 em 2000 para 161 em contraste com o que se passou entre os países do Leste Asiático onde os termos de troca passam de 100 em 2000 para 72 (UNCTAD, Handbook, 2013) e os países desenvolvidos em geral.

Se a urbanização constitui o primeiro motor e polo de expansão autônoma direta da demanda para os países ricos em recursos naturais, o segundo motor é o da transformação da China num grande centro manufatureiro da economia mundial e que se transmite para os demais países através de suas exportações industriais (de bens intermediários e finais), do seu efeito sobre os seus preços e por meio das importações de matérias-primas, bens de capital e de partes e componentes das cadeias produtivas em que a China está inserida. Neste processo a China não constitui uma fonte de demanda autônoma da economia mundial na medida em que a demanda sobre o resto do mundo está associada ao crescimento de seus mercados externos. Os maiores mercados formados pelos países industrializados, os EUA, a

\footnotetext{
${ }^{3}$ Já há uma extensa literatura sobre o efeito da expansão da China sobre o preço das commodities. A principal convergência é a constatação de que este efeito foi concentrado em alguns minerais ferrosos (minério de ferro) e não ferrosos como o cobre e algumas mercadorias agrícolas como o farelo de soja e insumos industriais como o algodão. Em minerais como a bauxita, cobre, zinco a demanda chinesa supera $30 \%$ da demanda mundial, em algodão, farelos, minério de ferro, a demanda chinesa explica cerca de $60 \%$ do acréscimo do comércio mundial (Farooki e Kaplinsky, 2012; Serrano, 2013).

${ }^{4}$ Considerando o preço médio das commodities igual a 100 em 2000, em 2012 este preço era de 277,0 (a queda substancial ocorrida em 2009 foi revertida nos anos subsequentes). A valorização dos metais e da energia foi ainda muito maior do que a das commodities agrícolas, entre estas se destacaram óleos comestíveis, entre os metais o cobre e o minério de ferro se destacaram.
} 
UE e o Japão cresceram relativamente pouco na última década, particularmente pós-2008, e a expansão da parcela do mercado chinesa se deu, em parte, pela redistribuição do peso das economias asiáticas no mercado americano e da UE a favor da China. Ainda que relativamente pequena $-7,2 \%$ das importações dos países em desenvolvimento em 2010 originavam-se da China (Farooki e Kaplinsky, 2012) - a expansão dos mercados destes países foi importante para a elevada expansão das exportações industriais deste país. Entre 1995 e 2012 a parcela das exportações chinesas exportadas para as economias em desenvolvimento passou de 46,3 para $51,2 \%$. Ainda que a parcela maior destas exportações seja para as economias asiáticas, foram as demais economias em desenvolvimento, em particular na América Latina e África, que aumentaram sua participação nas exportações totais chinesas (UNCTAD, Handbook, 2013).

Para os supridores de partes e componentes da produção chinesa, este segundo processo de expansão pôs em marcha uma grande complementaridade. A despeito de disputas comerciais localizadas, desenvolveu-se na China uma estrutura fortemente complementar com a economia dos EUA, do Japão e Coreia, principais fornecedores de bens (e serviços) intermediários de maior conteúdo tecnológico. Este comércio e esta "complementaridade em tarefas" da China com os EUA e demais supridores de partes e componentes está na base da rivalidade das exportações chinesas com os demais exportadores mundiais tanto em setores como vestuário, calçados, móveis como em eletrônica de consumo, computadores e bens de capital nos países em desenvolvimento mais diversificados.

\section{O "EFEITO DEMANDA” E O “EFEITO ESTRUTURA" DA EXPANSÃO CHINESA}

Como resultado destes dois processos, a expansão Chinesa gerou dois efeitos distintos sobre os países, um "efeito demanda" ou macroeconômico que se exerce através do seu impacto sobre as exportações, balança comercial, e investimentos ${ }^{5}$ e um "efeito estrutura" ou setorial através do seu desigual impacto sobre os setores ou atividades segundo o grau de complementaridade e de rivalidade. Dependendo das características dos países, da dotação de recursos naturais, do seu tamanho, do estágio tecnológico e das políticas econômicas domésticas, a combinação de ambos os efeitos gera diferentes resultados sobre o crescimento econômico ${ }^{6}$.

\footnotetext{
${ }^{5} \mathrm{O}$ "efeito demanda" induzido pelo aumento das exportações é tanto maior quanto mais expansiva for a política econômica bem como a distribuição interna de seus ganhos daí derivada. Para uma discussão dos dois efeitos na economia asiática ver Medeiros (2006).

${ }^{6}$ A já extensa literatura sobre a "doença holandesa" (Bresser, 2010) examina os efeitos negativos decorrentes da valorização da taxa real de câmbio associado ao boom das commodities sobre a estrutura produtiva e exportadora da economia. $\mathrm{O}$ aumento da propensão a importar e a primarização da pauta exportadora levariam a desindustrialização e baixo crescimento. Evidentemente que estes efeitos diretos são muitos desiguais entre as economias segundo o grau de industrialização e a estrutura exportadora - mui-
} 
Em relação ao aumento das exportações e o crescimento a ela associada é importante considerar uma via direta - o aumento das exportações para a China - e uma indireta (Kaplinsky e Messmer, 2008). Esta última ocorre quando as exportações para terceiros mercados aumentam em decorrência do efeito expansivo sobre a capacidade de importar destes países. Estes impactos podem ser maiores ou menores dependendo do crescimento das importações associada a esta expansão e, consequentemente, da posição do balanço de pagamentos.

Em relação ao "efeito estrutura" há de um lado a complementaridade entre a demanda chinesa por commodities e a sua exportação industrial e de outro, uma rivalidade entre esta e a produção e exportação industrial competitiva. Tal como sublinhado por Kaplinsky e Messner (2008) a rivalidade entre a produção made in China e as economias produtoras dos bens industriais que a expansão chinesa desloca ou desafia se dá diretamente sobre os mercados internos e indiretamente através do seu efeito sobre os mercados externos. Em relação a estes a maioria dos estudos baseia-se na formulação sugerida por Lall e Weis (2005) que avalia o impacto da China sobre uma dada economia através do seu efeito sobre a evolução da parcela de mercado dos bens industriais exportados por esta. Assim, por exemplo, quando há uma queda da parcela de mercado das exportações latino-americanas para os EUA e, simultaneamente, um aumento da parcela da China neste mercado haveria uma "ameaça direta"; quando ambas as parcelas aumentam, mas a chinesa cresce a uma taxa mais alta haveria uma “ameaça parcial”. A perda dos mercados externos e internos e a "primarização da pauta exportadora" conjugariam assim o maior risco da ascensão chinesa (Jenkins e Barbosa, 2012).

Embora este esquema seja bastante útil devem-se considerar duas qualificações. Como para o país o que interessa é a taxa de crescimento das exportações é possível que devido ao "efeito demanda" as exportações industriais do país estejam crescendo para este mercado ainda que não necessariamente sua parcela devido a maior crescimento das exportações chinesas configurando uma "ameaça direta". Por outro lado, devido às transformações na estrutura do comércio mundial, a variável relevante sobre o efeito estrutura não se resume ao tipo de bem exportado (classificado segundo o seu conteúdo tecnológico) e, consequentemente, da parcela exportada deste bem no mercado mundial, mas a da atividade produzida (classificada segundo o seu conteúdo tecnológico) e, em consequência, a parcela do valor adicionado exportado. A elevação da parcela industrial exportada pelo país pode estar refletindo o crescimento das importações intermediárias e não informa muito sobre o progresso ou regresso tecnológico do país que esta relação supostamente deveria expressar.

to mais elevada nas economias petroleiras especialmente naquelas financeiramente desreguladas - e decorrem da ausência de políticas macroeconômicas e industriais contrarrestantes. Com a crise dos estados desenvolvimentistas e suas políticas industriais nos anos 1990, o boom das commodities possibilitou maior crescimento mas sem mudança estrutural. A novidade nos anos 2000 foi a maior persistência do ciclo das commodities e, consequentemente a maior taxa de crescimento das exportações. 
Entretanto, com exceção do México que está de fato inserido nas cadeias produtivas e suas exportações industriais possuem baixo valor adicionado, na maioria das economias da região, particularmente no MERCOSUL, a divisão em tarefas em cadeias de valor, com exceção da cadeia produtiva da indústria automobilística, não se desenvolveu predominando amplamente o comércio em bens finais. Desse modo, a despeito desta ressalva, a estrutura setorial, tal como considerado na maioria dos estudos empíricos, traduz de fato o maior ou menor grau de sofisticação tecnológica.

Antes de examinar os impactos diferenciados da ascensão chinesa para as economias latino-americanas, descrevem-se, na próxima seção, os principais canais e evidências da expansão chinesa na região.

\section{A EXPANSÃO CHINESA NA AMÉRICA LATINA (AL)}

O Quadro 1 apresenta as relações econômicas da AL com a China.

Quadro 1: China e América Latina: Relações Comerciais, Investimentos e Créditos chineses na região, de 2002 a 2011 (em milhões de dólares)

\begin{tabular}{|c|r|r|}
\hline & \multicolumn{1}{|c|}{ Com México } & \multicolumn{1}{|c|}{ Sem México } \\
\hline Volume Total Exportado para China & $395.496,7$ & $374.262,7$ \\
\hline Volume Total Importado da China & $(674.243,9)$ & $(407.243,6)$ \\
\hline Invstimentos Chinês & $25.999,0$ & $25.868,0$ \\
\hline Créditos Chineses & $73.215,0$ & $72.215,0$ \\
\hline SALDO & $(179.533,2)$ & $(65.102,1)$ \\
\hline
\end{tabular}

Fontes: Comtrade. Obs.: Dussels (2012), Gallagher (2012), Ellis (2009), FMI, World Bank.

As relações comerciais entre a China e países da AL começaram a se intensificar a partir de 2002, com o ingresso da China na OMC e pela maior ofensiva comercial a partir da visita de Hu Jintao em 2004, quando dezenas de acordos comerciais, de investimentos e de cooperação foram assinados com diversos países da região. Em 2011, a China exportou para a América Latina mais de US\$ 155 bilhões. Em 2002, do total exportado pelos países da América Latina 2,1\% foram para a China em 2011 esse número saltou para 9,8\%. Já quanto às importações, se em 2002 apenas $4,3 \%$ de tudo que era importado pelos países analisados vinham da China, em 2011 essa participação subiu para 16,4\%. O crescimento da participação chinesa nas importações totais dos países do continente aumentou, sem exceção. Em alguns países a participação chinesa cresceu em mais de 300\% de 2002 para 2011 (ver Quadro 2). Esta evolução levou a um importante déficit global da região a região com a China, que atingiu a cifra de US\$ 54,3 bilhões em 2011 ainda que muito diferenciado entre os países. Indiscutivelmente, esta posição deficitária é concentrada nas relações com o México, sendo que na América do Sul diversos países apresentaram superávit (ver Quadro 3). 
Quadro 2: Participação da China nas Exportações

e Importações nos Países Latino-Americanos

\begin{tabular}{|l|c|c|c|c|c|c|}
\hline & $\begin{array}{c}\text { Exportações } \\
2002(\%)\end{array}$ & $\begin{array}{c}\text { Exportações } \\
\mathbf{2 0 1 1}(\%)\end{array}$ & $\begin{array}{c}\text { Variação } \\
(\%)\end{array}$ & $\begin{array}{c}\text { Importações } \\
\mathbf{2 0 0 2}(\%)\end{array}$ & $\begin{array}{c}\text { Importações } \\
\mathbf{2 0 1 1}(\%)\end{array}$ & $\begin{array}{c}\text { Variação } \\
(\%)\end{array}$ \\
\hline Argentina & 4.2 & 7.4 & 76 & 3.7 & 15.7 & 328 \\
\hline Bolívia & 0.6 & 3.7 & 517 & 5.1 & 11.2 & 122 \\
\hline Brasil & 4.2 & 17.3 & 312 & 3.3 & 14.5 & 341 \\
\hline Chile & 7.0 & 22.8 & 226 & 7.2 & 16.9 & 137 \\
\hline Colômbia & 0.2 & 3.5 & 1650 & 4.2 & 15.0 & 256 \\
\hline Costa Rica & 3.7 & 37.6 & 916 & 1.8 & 8.4 & 376 \\
\hline Equador & 0.3 & 2.6 & 767 & 3.4 & 13.7 & 301 \\
\hline México & 0.4 & 1.7 & 325 & 3.7 & 14.9 & 300 \\
\hline Panamá & 0.3 & 0.3 & 0 & 41.9 & 66.8 & 59 \\
\hline Paraguai & 0.8 & 0.6 & & 12.7 & 29.6 & 133 \\
\hline Peru & 9.5 & 15.3 & 61 & 6.2 & 16.7 & 171 \\
\hline Uruguai & 5.6 & 4.3 & & 3.8 & 11.9 & 209 \\
\hline Venezuela & 0.6 & 12.8 & 2033 & 2.8 & 17.9 & 529 \\
\hline Total & 2.1 & 9.8 & 367 & 4.3 & 16.4 & 281 \\
\hline
\end{tabular}

Fonte: COMTRADE, elaboração própria.

As exportações da AL para a China concentraram-se em algumas poucas commodities (principalmente da soja no Brasil e Argentina, cobre e madeira no Chile, minério de ferro no Brasil e petróleo na Venezuela e Brasil). Em contraste, a elevação da capacidade de importar das economias latino-americanas voltou-se em boa parte para os produtos industriais chineses, tanto em bens finais quanto em bens de capital e produtos intermediários. (O Quadro 3 apresenta a estrutura e o saldo do comércio em países selecionados.)

Dos produtos importados, três setores — informática, máquinas e equipamentos e manufaturados diversos - responderam por $64,6 \%$ do total importado pela região em 2009 (Hiratuka, Castillo et al. (2012). Estes produtos aumentaram sua importância ao longo dos anos 2000, em detrimento de produtos mais tradicionais, como vestuário, brinquedos e calçados.

O Brasil, com uma economia mais diversificada que os demais países da América do Sul e com suas reservas extraordinárias de terras e minérios ocupa uma posição dominante entre os parceiros comerciais da China na $\mathrm{AL}^{7}$. Argentina e Uruguai têm na soja e seus subprodutos a principal commodity exportada para a

\footnotetext{
${ }^{7}$ Em relação às exportações brasileiras, a China é a principal cliente da Empresa Vale S/A. Em 2011, o minério de ferro representou $44,7 \%$ das exportações nacionais para o país asiático. Já para a commodity petróleo, em julho de 2006, a Petrobras assinou seu primeiro contrato de exportação com uma empresa chinesa, a Sinopec. Em 2011, a estatal brasileira vendeu US\$ 4,88 bilhões para a China, com alta de $802 \%$ em relação ao ano de 2005 . O aumento dos embarques se deve ao financiamento de US\$ 10 bilhões concedidos pelo Banco de Desenvolvimento da China à Petrobras, que tem como garantia a venda de petróleo da empresa à estatal Sinopec. Já as exportações agrícolas brasileiras para a China são
} 


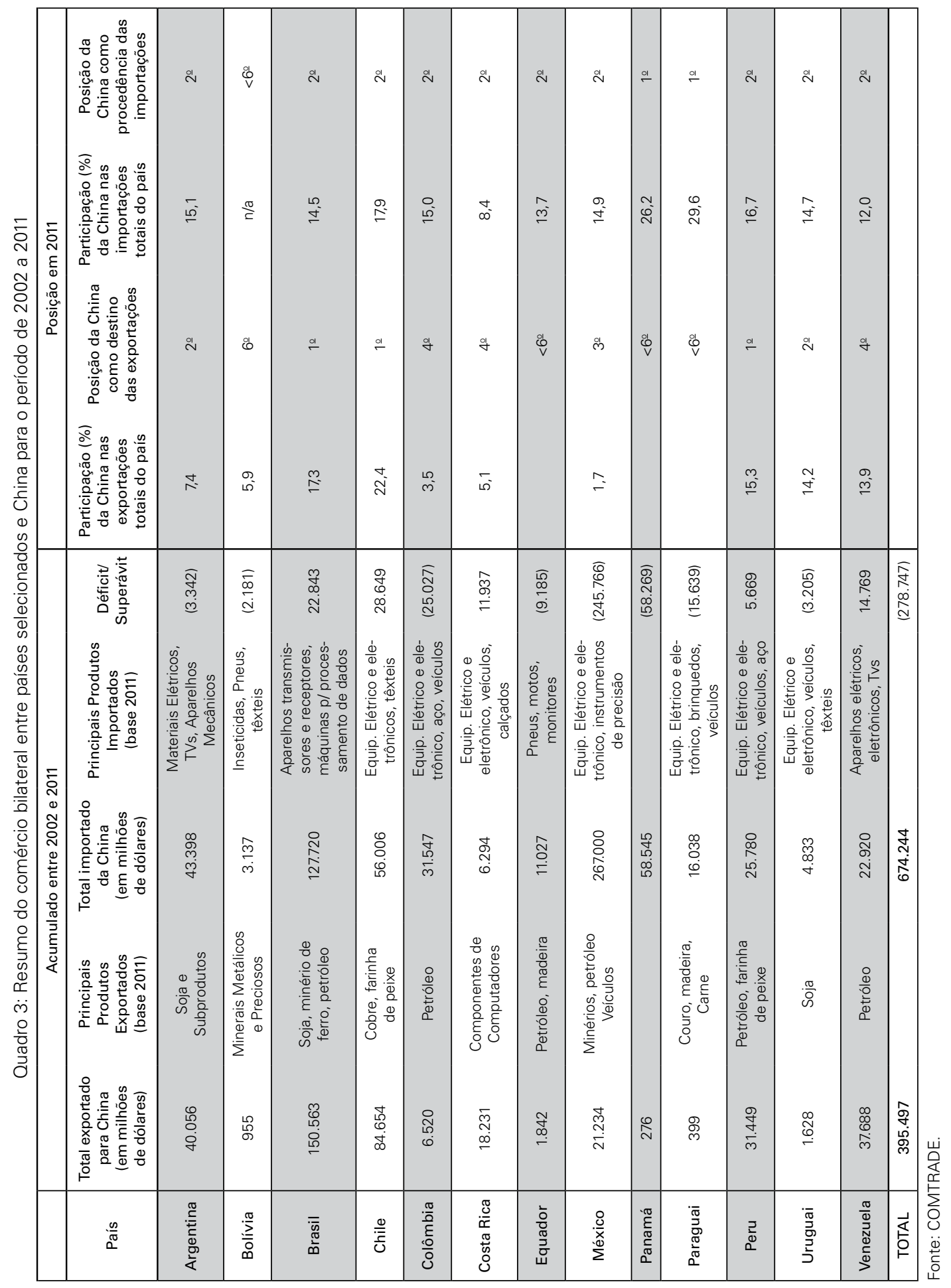


China. Em 2011, a soja representou aproximadamente 71\% do total exportado pela Argentina para o país asiático. Dos países andinos a China importa, praticamente, minérios, minerais e petróleo. Já a economia venezuelana é dominada pelo petróleo, principal produto exportado para a China (em 2011, 98\% do total exportado para a China foram de petróleo e seus subprodutos).

A despeito das reservas equatorianas de petróleo não serem tão grandes quanto às da Venezuela, para esses dois últimos países a China se tornou a maior fonte de financiamento. Na Bolívia, o interesse da China concentra-se mais nos minérios do que no seu gás ou petróleo ${ }^{8}$; no Peru no seu petróleo e minérios. Embora a produção de petróleo neste país seja pequena, novas descobertas foram feitas em 2006/07 em áreas operadas pelos chineses, tendo a produção saltada de 111 mil barris/dia em 2005 para 153 mil barris/dia em 2011 ${ }^{9}$. Por fim, a Colômbia também interessa à China por seu petróleo ${ }^{10}$.

Ao contrário dos países da América do Sul, no México além do peso dos produtos primários na sua pauta de exportação ser menor, a importação originária da China é centrada nos bens intermediários para a montagem final de produtos em seu território nacional para, posteriormente, serem reexportados para os EUA. O volume de importações provenientes da China está diretamente associado a produtos de informática e telecomunicações, além de produtos relacionados ao setor de máquinas e equipamentos. Esses dois segmentos juntos respondem por quase $70 \%$ das importações com origem na China e por um déficit comercial de dezenas de bilhões de dólares (em 2011, US\$ 46,3 bilhões). O comércio bilateral com a Costa Rica também é diferenciado. O país tem diversificado suas exportações para a China com produtos tradicionais (café, frutas, outros alimentos) porém, componentes de computadores, principalmente chips (Intel), continuam a ser os principais produtos exportados, ou seja, $94,5 \%$ do total exportado para o país asiático em 2011. Já o Panamá não possui commodities de interesse chinês, portanto o interesse da China nesse país se resume, basicamente, em dois tópicos: o Canal do Pana-

dominadas por grãos e óleo de soja. Em 2011, o Brasil exportou para os chineses 22,1 bilhões de toneladas do produto, responsável por $41,9 \%$ do total importado pela China.

${ }^{8}$ Estima-se que os depósitos de ferro em El Mutún, localizados na região de Santa Cruz, sejam os maiores da América do Sul.

${ }^{9}$ O cobre peruano também é de interesse chinês; em 2008, a Chinalco ganhou um contrato de concessão de US\$ 2,15 bilhões para operar a mina de cobre Toromocho, a maior do país.

${ }^{10} \mathrm{Em} 2005$, a agência de hidrocarbonetos colombiana assinou um memorando de entendimentos com a China National Oil Development Corporation (CNODC) para exploração e produção de petróleo. Embora as reservas provadas de petróleo colombiano sejam modestas, em 2006 a empresa chinesa Sinopec, em parceria com uma empresa indiana, a ONGC Videsh Ltd., comprou $50 \%$ de participação da Omimex (indústria local de exploração e produção) por US\$ 850 milhões. Em outubro de 2009, a chinesa Sinochem Group comprou a Emerald Energy PLC que possuía na Colômbia o direito de exploração e produção em oito blocos. 
má e o fato do país ainda reconhecer diplomaticamente Taiwan como o governo legítimo da China ${ }^{11}$.

A ofensiva comercial da China tem sido abrangente. Até dezembro de 2012 a China havia promovido três acordos de livre comércio com países da região Chile, Peru e Costa Rica. Além do minério de ferro, cobre soja e petróleo, outros produtos primários também têm aumentado suas exportações para a China, como madeira, papel e celulose, carne, café, etc. Os investimentos diretos (IED) chineses destinados a América Latina embora relativamente pequenos (tanto em relação ao total dos fluxos de investimento chineses para o mundo quanto em relação aos fluxos recebidos pela região) têm crescido a elevadas taxas. A busca de recursos constitui a principal estratégia do IED chineses: $86 \%$ do IED chinês na América Latina durante o período de 1990-2010 foram para os setores de energia e de recursos naturais. Mas os recentes investimentos na indústria de transformação deixam claro que o mercado latino-americano tornou-se progressivamente importante para as empresas chinesas em sua busca por novos mercados ${ }^{12}$.

\section{OS IMPACTOS DA EXPANSÃO CHINESA NA AMÉRICA LATINA}

$\mathrm{Na}$ última década a $\mathrm{AL}$ acumulou um déficit comercial com a China - Quadro 1-e a despeito do seu forte crescimento, as exportações para este país ainda constituem uma parcela relativamente pequena das exportações da região (inferior a $10 \%$ das exportações em 2011). Este quadro, como se observou - Quadros 2 e 3 - é bastante desigual entre os países. Mas os impactos de demanda mais importantes foram indiretos e a taxa de crescimento das exportações totais e a evolução dos termos de troca constituíram seus principais componentes. A elevação do preço das commodities permitiu um crescimento generalizado das exportações tanto dirigido diretamente para a China - contribuindo em muitas delas para um saldo comercial elevado - quanto para o resto do mundo; por outro lado, no caso das economias mais diversificadas (Argentina e Brasil) o maior crescimento dos países primário especializados permitiu aumentar as exportações não apenas de commodities mas a de bens industriais (ainda que a taxas menores) para estes mercados, gerando inclusive superávit comercial com os países da América do Sul ${ }^{13}$. (ver Quadro 4)

\footnotetext{
${ }^{11}$ Os países da América Central são fontes residuais de recursos minerais e agrícolas, assim como mercados para os chineses. O interesse chinês pela região é mais político (23 países reconhecem Taiwan como um estado soberano, 12 encontram-se na América Latina e no Caribe).

${ }^{12}$ A Chery, começou a montar seu modelo QQ no Uruguai com parceiros locais para ser comercializado na América do Sul; Tiens, estabeleceu redes de vendas diretas na Argentina, Brasil, Colômbia, Equador, México, Peru e Venezuela e a empresa Gree, maior produtora de aparelhos de ar-condicionado do mundo, e estabeleceu uma fábrica no Brasil (Fornes e Butt-Phillip, 2012).

${ }^{13}$ Ver Hiratuka et al. (2010). O único país que não parece se beneficiar do "efeito demanda" da China em suas relações comerciais com os demais países da região é o México. O Brasil foi o país que mais se
} 
Quadro 4: Evolução dos Termos de Troca,

Exportações e Saldo Comercial na América Latina

\begin{tabular}{|l|l|l|l|l|}
\hline & $\begin{array}{l}\text { Poder de } \\
\text { Compra das } \\
\text { Exportações } \\
\text { em 2012 } \\
(2000=100) *\end{array}$ & $\begin{array}{l}\text { Termos } \\
\text { deTroca } \\
\text { em 2012** } \\
(2000=100)\end{array}$ & $\begin{array}{l}\text { Evolução das } \\
\text { Exportações } \\
\text { Totais entre 2000 } \\
\text { e 2010 (\% médio } \\
\text { anual do país ou } \\
\text { grupo de países) }\end{array}$ & $\begin{array}{l}\text { Saldo Comercial } \\
\text { com o } \\
\text { MERCOSUL e } \\
\text { Associados*** } \\
\text { (entre 2002 e 2009) }\end{array}$ \\
\hline Argentina & 249 & 161 & 11.8 & Superávit \\
\hline Brasil & 244 & 129 & 15.5 & Superávit \\
\hline $\begin{array}{l}\text { Economias Agrícolas } \\
\text { (Paraguai, Uruguai, } \\
\text { Colômbia) }\end{array}$ & 381 & 122 & 17.2 & $\begin{array}{l}\text { Superávit (Colômbia) } \\
\text { Déficit (Paraguai, } \\
\text { Uruguai) }\end{array}$ \\
\hline $\begin{array}{l}\text { Economias Mineiras } \\
\text { (Bolívia, Chile, Peru) }\end{array}$ & 384 & 175 & 19.7 & Deficit \\
\hline $\begin{array}{l}\text { Economias Petroleiras } \\
\text { (Equador, Venezuela) }\end{array}$ & 253 & 198 & 14.3 & Deficit \\
\hline
\end{tabular}

*Calculado como o índice do valor das exportações deflacionado pelo índice de valor unitário das importações; ** calculado como a razão entre o índice de valor unitário das exportações e o das importações; *** Brasil, Chile, Colômbia, Equador, Uruguai, Bolívia, Paraguai, Venezuela, Argentina e Peru

Fonte: COMTRADE, UNCTAD, Handbook of Statistics, 2013; MRE, DIC, 2010.

Quando se considera o peso das exportações nos países da América do Sul, duas observações se destacam. A primeira foi a substancial elevação ocorrida (UNCTAD, 2013), a segunda é a substancial diferença entre as economias: na Bolívia, Chile, Equador, Paraguai, Peru, Suriname, as exportações formam um componente superior a 30\% do PIB; no Brasil, esta razão é muito menor e se manteve; entre as economias maiores, apenas a Argentina passou por um aumento importante (de $11 \%$ em 2000 para cerca de $22 \%$ em 2011). Se nas economias primárias exportadoras especializadas o maior crescimento do PIB decorreu em boa parte do aumento das exportações, no Brasil, na Colômbia e na Argentina este aumento foi importante devido ao seu impacto sobre o balanço de pagamentos viabilizando maior taxa de crescimento puxado pelo consumo interno e investimentos (CEPAL, 2012).

Como o maior impacto da ascensão chinesa recaiu sobre o preço e a demanda dos metais, os países mineiros, com alta razão de comércio e especializados nesta produção, como o Chile, o Peru (que assinaram acordo de livre comércio com a China $)^{14}$ e a Bolívia tiveram sua taxa de crescimento influenciada direta ou indire-

beneficiou através de suas exportações industriais do crescimento global da América do Sul induzido pela expansão chinesa. Esta mesma conclusão foi obtida por Cunha, Lélis e Bichara (2013) sobre a expansão das exportações brasileiras para a América Latina.

${ }^{14}$ Estes países formaram em 2012, junto com o Equador, México e Colômbia, a "Aliança do Pacífico", um arranjo favorecedor ao livre comércio com a China. 
tamente pela taxa de crescimento da China. As exportações de minérios foram essencialmente concentradas no Brasil, Chile e Peru mas no caso do Brasil a expansão chinesa foi mais importante para a composição de sua pauta de exportações do que diretamente para o seu crescimento. A dependência maior da pauta exportadora às commodities ocorrida na América do Sul "primarização"—foi uma conseqüuência geral desta expansão. No caso do Brasil ela foi importante devido à simultânea presença do país tanto nos minérios quanto na soja, quanto na energia.

Considerando os impactos da expansão chinesa sobre a estrutura produtiva e especialização exportadora deve-se observar a formação dos dois padrões de comércio no continente: um típico da América do Sul, baseado na complementaridade entre as exportações de produtos primários - especialmente concentradas em minério de ferro, cobre e soja - e importação diversificada de bens industriais; outro, entre o México e a China - onde a montagem de produtos eletrônicos e a indústria têxtil e vestuário concorrem diretamente no mercado americano - em que a rivalidade e competição industrial predominam. Ainda que em menor dimensão, a rivalidade tanto nos mercados domésticos quanto em terceiros mercados também se afirmou para os países da América do Sul dependendo do seu grau de industrialização.

O "efeito China" sobre a indústria da região decorreu da interação entre os baixos custos unitários do trabalho em dólares da sua produção e os maiores custos e a ausência na maioria dos países de políticas econômicas e industriais voltadas à diversificação produtiva. Estas, historicamente ausentes ou desmontadas ao longo dos anos 1990 não foram reconstruídas de forma abrangente na última década em que pese alguns esforços localizados em alguns países e iniciativas regionais (CEPAL, 2012). Entre os países menos industrializados e primários especializados, o deslocamento dos produtores domésticos de seus mercados internos em setores tradicionais e intensivos em mão de obra - em que a têxtil e o setor de vestuário são os casos mais notáveis - constitui o principal efeito de deslocamento e maior ameaça aumentando potencialmente sua vulnerabilidade externa decorrente da dependência às commodities. Entre os mais industrializados, tanto no México como o Brasil e a Argentina na América do Sul, embora este efeito esteja presente incluindo não apenas estes setores, mas aqueles de maior conteúdo tecnológico particularmente na eletrônica de consumo e bens de capital, a perda relativa ou absoluta da parcela de mercado dos produtores industriais domésticos para as exportações chinesas (nos EUA no caso do México, no MERCOSUL no caso do Brasil) constitui um desafio central ${ }^{15}$ com impactos importantes ainda que diferenciados sobre a estrutura global das exportações.

\footnotetext{
${ }^{15}$ Diversos trabalhos recentes (Hiratuka et al. 2012; Dussel-Peters e Gallagher, 2013; Jenkins e Barbosa, 2012; Cunha, Lélis e Bichara, 2013) examinaram o impacto da expansão comercial da China sobre a estrutura exportadora latino-americana a partir da base de dados da COMTRADE documentando estes efeitos intersetoriais e o impacto sobre terceiros mercados.
} 


\section{NOTAS FINAIS}

A expansão chinesa afirmou-se como polo autônomo de demanda sobre os países da América do Sul produtores de alimentos, minérios e energia. A sua afirmação como centro manufatureiro mundial deslocou exportações competitivas dos principais mercados mundiais incluindo as da região. Discutiu-se o "efeito demanda" e o "efeito estrutura" da expansão chinesa e seus impactos nos países segundo o grau de complementaridade e de rivalidade. Argumentou-se que o "efeito deman$\mathrm{da}$ " da ascensão chinesa contribuiu diretamente para o crescimento e indiretamente para o relaxamento da restrição externa observado na América do Sul. Devido ao elevado crescimento tanto do volume quanto dos preços das commodities aumentou em todos os países da América do Sul a parcela destas exportações sobre as exportações totais. No caso do Brasil (e em menor proporção na Argentina) houve a conjugação de dois efeitos. De um lado, a maior expansão da capacidade de importar dos países do MERCOSUL permitiu ao país aumentar suas exportações industriais por outro lado, a despeito desta expansão, as exportações chinesas para a região - particularmente na eletrônica de consumo, produtos intermediários e de capital - cresceram a um ritmo mais alto resultando num deslocamento parcial do país do seu principal mercado industrial.

Com a desaceleração do crescimento econômico entre os países da América do Sul e simultaneamente com a maior penetração das importações made in China as restrições ao crescimento deste país provenientes do canal do comércio poderão aumentar com efeitos negativos para o MERCOSUL. Entretanto, os fatores estruturais que contribuíram para a elevação do preço das commodities e dos termos de troca continuam presentes. Embora o ritmo de crescimento chinês tenha se reduzido a atual estratégia chinesa tem sido a de ampliar a oferta de bens e serviços urbanos para os imigrantes irregulares e expandir o consumo interno; por outro lado, se em relação aos alimentos poucos países ainda possuem fronteira agrícola em expansão (Farooki e Kaplinsky, 2012) entre os metais e a energia os esforços de eficiência no uso de recursos e renovação de fontes energéticas que se afirmaram na indústria mundial dificilmente resultarão numa quebra estrutural nos preços destas commodities. Os termos de troca e a demanda derivada da expansão chinesa continuam favoráveis ao crescimento econômico regional, aproveitá-las, entretanto, depende de políticas industriais cuja ausência nos últimos anos ou a baixa prioridade a elas conferida seguramente colaborou para a redução das perspectivas de diversificação produtiva na região.

\section{REFERÊNCIAS BIBLIOGRÁFICAS}

BRESSER-PEREIRA, Luiz Carlos (2010) Globalização e Competição, São Paulo, Campus, Elsevier. CEPAL (2012) Cambio Estructural para la Igualdad, Uma Visión Integrada del Desarrollo, Santiago, Naciones Unidas 
CEPAL (2013) Anuário Estadístico de América Latina y el Caribe, Santiago, Naciones Unidas.

COMTRADE (2012). United Nations Commodity Trade Statistics Database.

CRI (2010). Cúpula Empresarial China - América Latina defende desenvolvimento comum, 21 out. Disponível em: <http://portuguese.cri.cn/561/2010/10/21/1s127883.htm/>.

CUNHA, André Moreira, LÉLIS, Marcos Tadeu C.; BICHARA, Julimar da Silva (2013). "Impactos da ascensão da China na inserção internacional do Brasil”. IN: CASTRO, Inez Silvia Batista (org.), Novas Interpretações Desenvolvimentistas, Centro Celso Furtado.

DUSSEL-PETERS, Enrique (2012). “Chinese FDI in Latin America: Does Ownership Matter?” Working Group on Development and Environment in the Americas. Discussion Paper Number 33, nov.

DUSSEL-PETERS, Enrique; GALLAGHER, Kevin P. (2013). "Nafta's Uninvited guest: China and the sisientegration of North American Trade”. CEPAL Review, 110.

ELLIS, R. E. (2009). "China in Latin America: The Whats and Wherefores”. EUA: Lynne Rienner Publishers.

FAROOKI, Masuma; KAPLINSKY, Raphael (2012). "The Impact f China on Global Commodity Prices”. New York, Routledge.

FMI (2011). "Western Hemisphere. Shifting Winds, New Policy Challenges”. Washington, DC.

FORNÉS, Gastón; PHILIP, Alan B. (2012). "The China-Latin America Axis. Emerging Markets and the Future of Globalisation”. Nova York: Palgrave Macmillan.

JENKINS, Rhys; FREITAS Barbosa, Alexandre (2012). "Fear for manufacturing? China and the Future of Industry in Brazil and Latin America". The China Quarterly.

HIRATUKA, Célio; CASTILHO, Marta; DUSSEL-PETERS, Enrique; BIANCO, Carlos, CARRACELA, G. (2012). "Relações Comerciais entre América Latina e China: Caracterização da Evolução Recente”. IN: BITTENCOURT, Gustavo (coordenador): El Impacto de China em America Latina: Comércio e Inversiones, Red Mercosur de Investigaciones Econômicas, Uruguai.

KAPLINSKY, Raphael; MESSNER, Dirk (2008). "Introduction: The Impact of Asian Drivers on the Developing World”. World Development, Vol 36 n 2.

LALL, Sanjaya; WEISS, John (2005). "China's competitive threat to Latin America: an analysis for 1990-2002”. Oxford Development Studies, Vol 33, No 2.

MEDEIROS, Carlos A. (2006). “A China como um Duplo Polo na Economia Mundial e a Recentralização Asiática” REP, Vol 26, n 3 (103) julho setembro pp 381-401

MILLER, Tom (2012). "China's Urban Billion: The Story Behind in the Biggest Migration in Human History”. New York, Zed Books.

PAZ, Gonzalo S. (2011). “China and Venezuela: Oil, Technology, and Socialism”. IN: China Engages Latin America. Tracing the Trajectory. Adrian H. Hearn e José Luis León- Marnríquez,. Colorado, EUA: Ed. Lynne Rienner Publishers, pp. 221-234.

PREBISCH, Raul (1950) 'The Economic Development of Latin America and Its Principal Problems', Nova York, Nações Unidas

SERRANO, Franklin (2013). "Continuity and Change in the International Economic Order: Towards a Sraffian Interpretation of the Changing Trend in Commodity Prices in the 2000s". IN: LEVRERO, Enrico Sergio, PALUMBO, Antonella, STIRATTI, Antonella: Sraffa and the Reconstruction of Economic Theory; volume Two, New York, Palgrave Macmilan.

UNCTAD (2013) Handbook of Statistics, United Nations.

WORLD Bank, (2010). China Quaterly Update. 